\title{
REGULAMENTAÇÃO E GESTÃO DE ESTÁDIOS DE FUTEBOL NO BRASIL
}

\author{
Cacilda Mendes dos Santos Amaral \\ Universidade de São Paulo, São Paulo, São Paulo, Brasil \\ Flávia da Cunha Bastos \\ Universidade de São Paulo, São Paulo, São Paulo, Brasil
}

\begin{abstract}
Resumo
As leis brasileiras que dispõem sobre normas de proteção e defesa do torcedor preveem o direito à segurança nos estádios, acessibilidade, higiene e à qualidade das instalações físicas dos estádios, dentre outros fatores (BRASIL, 2003, 2010), mas a realidade está longe disso. Este estudo teve por objetivo analisar as regulamentações brasileiras para estádios de futebol e compará-las com as europeias e a da FIFA. Através de análise documental e bibliográfica constatou-se que as regulamentações brasileiras em comparação com as da UEFA e da FIFA apontam atraso e ineficiência, tanto em termos de adequação da estrutura quanto de serviços nos estádios de futebol. Conclui-se que esta ineficiência é um dos fatores que contribuem para o mau estado em que se encontram os estádios de futebol, resultando em limitações em termos da sua gestão.
\end{abstract}

Palavras-chave: Instalações Esportivas - Estádios de Futebol - Regulamentação

\section{Introdução}

$\mathrm{O}$

Brasil vive uma enorme expectativa em torno de um dos maiores eventos esportivos do planeta, a Copa do Mundo de Futebol, que se realizará no ano de $2014 \mathrm{em}$ terras brasileiras. Este fato nos leva a pensar na real possibilidade do Brasil em realizar este evento cumprindo as exigências de qualidade dos estádios, tal como aconteceu nas últimas edições do evento, perante as condições em que se encontram as instalações esportivas - estádios - no país.

As instalações esportivas passaram por modificações ao longo dos anos e as normas que as regulamentam passaram a ser norteadoras da gestão de equipamentos esportivos no que diz respeito ao controle de qualidade destas instalações. Dentre as regulamentações da Fédération Internationale de Football Association (FIFA) há um caderno de encargos que prevê, dentre outros aspectos, determinações para a cons- 
trução do estádio (tópicos de planejamento da construção); a segurança; a regulamentação da área de jogo; o conforto e a acessibilidade dos espectadores; a hospitalidade e a estrutura para acomodar a mídia (FÉDÉRATION INTERNATIONALE DE FOOTBALL ASSOCIATION, 2007).

Mas o que se vê no Brasil, infelizmente está longe do que seria o cumprimento destas exigências feitas pelo órgão máximo do futebol. Mesmo em termos de outros tipos de instalações esportivas, a primeira tentativa de regulamentar as instalações esportivas no país é encontrada na obra de Maria Lenk, publicada em 1941, que versava sobre administração da educação física e abordava questões a respeito da construção de piscinas, parques infantis, instalações de remo, aparelhamento para Educação Física. Outra obra surgiu em 1945, a primeira edição do livro "Dêem Estádios ao Exército" do então Capitão Jair Jordão Ramos (RIBEIRO, 2006), um manual que contém dados e explicações sobre a construção de instalações utilitárias e esportivas.

No decorrer do século XX outras publicações tiveram destaque no que diz respeito à construção e gestão de instalações esportivas no Brasil, mas nenhuma delas tratava exclusivamente de estádios de futebol ou trazia em seu conteúdo o tema (RIBEIRO, 2006). Durante a década de 90 , o futebol brasileiro passou por um período de dificuldades financeiras, vários clubes faliram, e a decadência pelas quais alguns outros clubes que não fecharam as portas passaram se traduziu também na falta de segurança em espetáculos esportivos e as próprias instalações destes clubes (CURI et. al., 2008).

O primeiro levantamento sobre os estádios de futebol no país, o Cadastro Nacional de Estádios de Futebol (CBF, 2009), indica que o Brasil possui 634 estádios de futebol. Esse levantamento levou em consideração as informações obtidas pela CBF (Confederação Brasileira de Futebol) junto às Federações Estaduais de Futebol. Deste número, 444 estádios, ou seja, aproximadamente $70 \%$, já receberam jogos oficiais de futebol profissional em partidas válidas pelos Campeonatos Brasileiros das séries A, B, C e D, além da Copa do Brasil.

Dentre os estádios cadastrados pela entidade máxima do futebol no Brasil, apenas 4,9\% deles tem capacidade superior a 30 mil espectadores (Quadro 1), número mínimo exigido pela FIFA para jogos internacionais. Além disso, há uma concentração destas instalações nas regiões sudeste e nordeste do país no que diz respeito às instalações com capacidades superiores a 30 mil assentos (CBF, 2009). 
Tabela 1: Estádios com capacidade superior a 30 mil espectadores por região.

\begin{tabular}{|lcc|}
\hline Brasil & Quantidade & Porcentagem \\
\hline Norte & 2 & 6,5 \\
\hline Nordeste & 9 & 29,0 \\
\hline Sudeste & 9 & 29,0 \\
\hline Sul & 6 & 19,4 \\
\hline Centro-Oeste & 5 & 16,1 \\
\hline TOTAL & 31 & 4,9 \\
\hline
\end{tabular}

Adaptado de: Cadastro Nacional de Estádios de Futebol (CBF, 2009).

Os estádios em território brasileiro, como relatado pela $\mathrm{CBF}$, são em sua maioria antigos e estão em condições precárias. Quase que em sua totalidade, as instalações brasileiras foram construídas entre as décadas de 1960 e 1980 e desde então suas estruturas se apresentam cada vez mais deficitárias. Apesar dos estádios estarem relativamente distribuídos pelo território nacional e possuírem grande diferença nas datas de suas construções (por volta de 20 anos), La Corte (2007) destaca que existem alguns fatores comumente encontrados nos estádios brasileiros de futebol, como o uso maciço de concreto em suas construções, a presença de pistas para a prática de atletismo ao redor do campo de futebol e a problemática de manutenção e gestão destes estádios.

Ao contrário do quadro verificado no Brasil, a Ásia e a Europa apresentam grande aumento na construção de novos estádios nos últimos quinze anos, principalmente devido a esses continentes terem sido sede de edições da Copa do Mundo de Futebol (Japão e Coréia em 2002, Alemanha em 2006), dos Jogos Olímpicos de Verão (Atenas 2004 e Pequim 2008) e de importantes campeonatos europeus de futebol (Euro Copa e Champions League), eventos que sem dúvida catalisaram a construção de novas e modernas instalações nos países/cidades-sede (LA CORTE, 2007).

Não é comum ao panorama nacional a adequação dos estádios. A única iniciativa deu-se no Rio de Janeiro, com a construção do estádio João Havelange, em 2007, para a realização dos Jogos Pan Americanos. Entretanto, eventuais obras de manutenção corretiva são realizadas nos mesmos, ou seja, reformas com objetivo de remediar problemas estruturais ou de segurança (LA CORTE, 2007). 
Na perspectiva econômica, a renovação, reforma ou construção de estádios, sejam públicos ou privados, deveria ser encarada como imprescindível uma vez que a instalação é também um produto da Indústria do Esporte, e como tal, influencia a atração dos consumidores do esporte frente a outras atrações concorrentes do espetáculo esportivo (MULLIN; HARDY; SUTTON, 2000). Em termos das organizações de prática, o estádio tornou-se uma unidade de negócio para o clube, com a venda de ingressos tanto para jogos como para shows, venda de camarotes e espaços de publicidade, além da preocupação com o conforto dos espectadores, que estão cada vez mais exigentes ao frequentarem os estádios de futebol.

Diante desta situação que se vê no Brasil, o presente estudo teve por objetivo analisar as regulamentações brasileiras para estádios de futebol e compará-las com as regulamentações europeias e da FIFA, visando um entendimento da evolução das mesmas e apontar as possíveis deficiências das leis e normas brasileiras que regulamentam os estádios de futebol do país. Pretende-se com este estudo contribuir para a discussão do atual estado dos estádios brasileiros sob a ótica das leis e órgãos que os inspecionam e apontar possibilidades de melhoria na gestão desses equipamentos.

\section{Material e métodos}

O presente estudo, quanto aos fins, caracterizou-se como pesquisa exploratória, pois há pouco conhecimento acumulado e estruturado sobre o tema; descritiva e explicativa, uma vez que pretendeu expor características de determinada população ou fenômeno, a situação dos estádios de futebol no Brasil, e compreender as causas que levam a essas condições. Quanto aos meios, trata-se de pesquisa documental e bibliográfica (VERGARA, 2006).

As fontes bibliográficas compreenderam pesquisas e estudos a respeito da realidade dos estádios no país e as fontes documentais englobaram 1. levantamentos produzidos por entidades relacionadas ao futebol como Ministério do Esporte e Confederação Brasileira de Futebol, 2. Documentos internacionais norteadores, como os cadernos de encargos da FIFA e da Union of European Football Associations (UEFA) e respeito de estrutura para estádios de futebol, segurança, infraestrutura e licenciamento, e 3. Regulamentações (leis, decretos e portarias) brasileiras que dispõem sobre os direitos dos torcedores, das 
condições de segurança nos estádios e requisitos mínimos para que estes possam ser considerados aptos a receberem competições esportivas.

A análise dos resultados foi estruturada no sentido de se concentrar em três aspectos: a) histórico e evolução das regulamentações brasileiras e internacionais; b) comparação da evolução da regulamentação brasileira com as da FIFA e da UEFA, e c) compreensão e avaliação da situação brasileira em termos dos serviços oferecidos e da segurança dos torcedores frequentadores de estádios de futebol e implicações para a gestão das instalações.

\section{Resultados e discussão}

O conceito de instalação esportiva que se tem hoje na Europa foi construído ao longo dos anos após acontecimentos trágicos que fizeram com que as autoridades competentes voltassem sua atenção para as estruturas colocadas a disposição da população para o espetáculo esportivo.

É imensa a lista de tragédias que apresenta grande número de mortos e feridos em estádios de futebol europeu. No entanto, foi após o incidente no estádio de Sheffield Hillsborough, no ano de 1989 na Inglaterra, no qual 96 pessoas morreram (HOLZMEISTER, 2005), que providências drásticas no que diz respeito à reforma destes espaços foram colocadas em prática.

O marco da adequação das estruturas e dos serviços em termos internacionais se deu em 1990 com a promulgação, pelo Parlamento Inglês, do nono e mais importante relatório de regulamentação para os estádios: o Taylor Report. Neste relatório foram apontados como causas gerais das tragédias que ocorriam nos estádios ingleses a combinação de pobres instalações utilizadas pelo esporte e o deficitário sistema de gestão das multidões que assistiam aos jogos, tratadas muitas vezes com agressividade (SIR NORMAN CHESTER CENTRE FOR FOOTBALL RESEARCH, 2002).

$\mathrm{O}$ relatório final contou com 76 recomendações e ainda trouxe à luz da discussão temas como as pobres instalações e serviços no futebol, a venda de álcool nos estádios ou em suas proximidades (apontada como possível causa de desordem por parte da torcida), a atitude sensacionalista de jornais e televisão e os efeitos do hooliganismo e da segregação de espectadores (SIR NORMAN CHESTER CENTRE 
FOR FOOTBALL RESEARCH, 2002).

Dentre as recomendações feitas pelo relatório, destacamos:

- Restrição na capacidade dos estádios;

- Monitoramento do público pela polícia e comissários, que seriam treinados para este tipo de intervenção;

- Gradual troca dos chamados "terraces" (gerais) por locais com assento em todas as arquibancadas, sendo que para cada clube foi estipulado um prazo - para realizar esta reforma, dependendo da divisão que o time disputava;

- Revisão imediata dos certificados de segurança de todas as instalações;

- Nova provisão de serviços de emergência e primeiros socorros;

- Introdução de novas leis de acordo com o número de delitos ocorridos dentro dos estádios, incluindo manifestações de racismo (canções) e arremesso de objetos no campo.

A aplicação das orientações contidas no Taylor Report mudou drasticamente a conformação dos estádios britânicos e tornou-se popular em toda a Europa, uma vez que iniciou um processo de modernização de muitos estádios em outros países (SPAMPINATO, 2010).

Concomitantemente com o Taylor Report, outro documento foi redigido e começou a ser adotado pelos países da União Europeia no ano de 1985, o European Convention on Spectator Violence at Sport Events (ECSV) (UNIÃO EUROPÉIA, 1985), com objetivo de combater a violência nos estádios e em eventos esportivos (CURI et. al., 2008).

Em abril de 2000 foi aprovado pela UEFA um caderno de instruções a respeito de segurança em estádios de futebol. Em dezembro de 2003 o documento sofreu uma revisão e foi aprovado por um Comitê Executivo da UEFA, sendo implantado em 2004 (UNION OF EUROPEAN FOOTBALL ASSOCIATIONS, 2003). O Binding Safety and Security Instructions (UNION OF EUROPEAN FOOTBALL ASSOCIATIONS, 2003) determinava o tipo acomodação nos estádios em que são disputadas competições (internacionais, nacionais, de segunda divisão), procedimentos para venda de ingressos, inspeções da instalação, exigências e orientações para as forças de segurança que garantiriam a ordem nos jogos, requisitos para estas instalações (como número de portões, áreas de estacionamento, proteção para a área de jogo, sala de controle do estádio - sistema de monitoramento), proibição da distribuição de álcool, dentre outras. 
Fica claro que já neste momento as preocupações da União Européia a respeito da segurança nos estádios estavam bem avançadas e as instruções contribuíam de forma significativa para a organização do esporte no continente Europeu. Ainda neste documento já era previsto, em anexo, um plano contra as ações racistas em estádios de futebol, demostrando a preocupação da entidade não só com as questões de segurança, mas com as questões sociais como um todo (UNION OF EUROPEAN FOOTBALL ASSOCIATIONS, 2003).

No ano de 2006 a UEFA, lançou o documento UEFA Safety and Security Regulations, que previa, além dos quesitos já mencionados nas instruções de 2003, uma cooperação entre os responsáveis pela segurança, os responsáveis pelas inspeções nos estádios e os responsáveis pelo serviço de emergência, para que o trabalho fosse realizado de forma conjunta entre as entidades organizadoras envolvidas.

$\mathrm{O}$ suporte aos times visitantes também ganhou destaque e no tópico referente ao controle dos espectadores foram adicionadas questões como a ação policial e a possibilidade de transmissão de reprises das jogadas (os chamados replays) em telões instalados nos estádios. Questões que vão além da segurança começam a ser direcionadas cada vez mais ao conforto do espectador e dos participantes do espetáculo esportivo (UNION OF EUROPEAN FOOTBALL ASSOCIATIONS, 2006a).

Nesta mesma linha de ação, foi lançado no mesmo ano o UEFA Stadium Insfraestructure Regulations, no qual já era possível se verificar critérios definidos para a estrutura das áreas destinadas aos espectadores e à imprensa, às áreas vips e orientações e ações de combate ao doping (UNION OF EUROPEAN FOOTBALL ASSOCIATIONS, 2006b). Uma nova edição do UEFA Stadium Insfrastructure Regulations foi feita em 2010 (UNION OF EUROPEAN FOOTBALL ASSOCIATIONS, 2010a) na qual estão definidos critérios para as estruturas que devem ser apresentadas pelas instalações, e ainda no mesmo ano é apresentado o UEFA Club Licensing and Financial Fair Play Regulations, que tem por objetivos, dentre outros:

- Garantir um nível adequado de administração e organização dos clubes participantes da liga europeia;

- Adaptar os clubes a oferecer aos jogadores, espectadores e mídia, instalações seguras;

- Seguir no desenvolvimento dos clubes tanto no que diz respei- 
to aos aspectos financeiros, legais, profissionais, de esporte e de administração como de critérios para infraestruturas na Europa (UNION OF EUROPEAN FOOTBALL ASSOCIATIONS 2010b).

Neste documento ainda são determinados os direitos, deveres e responsabilidades de todas as partes envolvidas nos sistemas de licenciamento da UEFA, ou seja, as exigências mínimas para se tornar membro associado da UEFA e participar das competições de clubes da entidade, quanto a infraestrutura, ao esporte e as bases financeiras, administrativas e legais para o funcionamento dos clubes (UNION OF EUROPEAN FOOTBALL ASSOCIATIONS 2010b).

Fica evidente, ao se observar a evolução o conteúdo destes documentos e a profundidade e abrangência das questões abordadas, que a organização das entidades e dos clubes (incluindo a estrutura das instalações esportivas) na Europa se faz hoje de um modo mais profissional, voltada ao negócio futebol. Destacam-se claramente as etapas de construção pelas quais estes documentos passaram até o que se apresenta hoje: a gestão consciente de clubes e instalações esportivas.

No Brasil, a exemplo do que aconteceu na Europa, vários estádios de futebol que apresentavam estruturas deficitárias começaram também a colecionar um número preocupante de acidentes envolvendo morte de torcedores. O primeiro incidente que se tem notícia em estádios brasileiros deu-se em 1964 quando, em partida entre o Santos Futebol Clube e o Sport Club Corinthians Paulista na Vila Belmiro, uma das arquibancadas veio abaixo, deixando 181 torcedores feridos. Ainda na mesma década, em partida entre os mesmos clubes no estádio do Morumbi, após um tumulto, um dos muros do estádio foi derrubado e matou um torcedor (O ESTADO DE SÃO PAULO, 2007).

Os acidentes mais graves em instalações brasileiras ocorreram no Estádio Alberto Tavares da Silva em 1973, no Piauí, quando 5 torcedores morreram e outros 70 se feriram por causa do rompimento de uma grade de segurança; em 1992, quando ocorreram 3 mortes e 90 pessoas ficaram feridas no estádio do Maracanã, e em 1995, quando um muro do estádio da cidade de Taubaté caiu e 20 torcedores caíram no fosso que dividia o campo da arquibancada (O ESTADO DE SÃO PAULO, 2007).

Já os acidentes que tiveram maior repercussão no país ocorreram em 2000 no estádio de São Januário, do Clube de Regatas Vasco da 
Gama, e, em 2002, no estádio Brinco de Ouro da Princesa, em Campinas, onde 175 e 25 pessoas se feriram com a queda de alambrados, respectivamente.

Após constante descaso das entidades de administração do futebol brasileiro (Confederação e Federações) para com o público presente nos estádios e com os praticantes da modalidade, evidenciou-se a necessidade de uma legislação que melhor regulamentasse o espetáculo esportivo (REIS, 2010). Em 2002 tramitou no Congresso Nacional a primeira versão do Estatuto de Defesa do Torcedor (EDT), que foi encaminhada e sancionada pelo Presidente da República em 2003. Mas, mesmo com a promulgação e implementação da Lei $\mathrm{n}^{0} 10.671$, em maio de 2003 (BRASIL, 2003), a situação no futebol brasileiro não demonstrou grandes mudanças.

Somente após alguns anos os órgãos públicos começaram a assumir as responsabilidades diante da lei e a fiscalizar seu cumprimento (REIS, 2010). Esta fiscalização dependeria em parte da participação dos próprios torcedores, uma vez que foi determinada a presença de um Ouvidor para cada partida e deveria ser reportado a este quaisquer ocorrências que viessem a acontecer durante a partida (BRASIL, 2003).

No que diz respeito à segurança dos torcedores a Lei prevê em capítulo específico o direito à segurança do torcedor antes, durante $\mathrm{e}$ após a partida, além da acessibilidade aos portadores de deficiência ou com mobilidade reduzida ao estádio, monitoramento por câmeras para estádios com capacidade superior a 20.000 pessoas - este número foi alterado para 10.000 pessoas em 2010 por ocasião da alteração do ETD em alguns de seus artigos, pela Lei $\mathrm{n}^{0} 12.299$, com intuito de prevenir e repreender os fenômenos de violência nos estádios (BRASIL, 2010).

O EDT (BRASIL, 2003), prevendo as questões de alimentação e higiene, garante também ao partícipe do evento a higiene e a qualidade das instalações e dos produtos alimentícios oferecidos para venda nos locais dos jogos, além da proibição da prática de preços abusivos nos produtos vendidos dentro dos estádios, e é dado ao torcedor o direito de sanitários em número compatível com a capacidade de público do estádio e em condições de limpeza e funcionamento.

Ainda são previstos na Lei 10.671 tantos outros direitos como transporte público seguro e organizado, imparcialidade da arbitragem, comunicação entre o torcedor e a entidade de prática esportiva, dentre 
outros. Mas a realidade que encontramos nos estádios brasileiros é bem diferente do que a lei preconiza e pode ser comprovada facilmente por qualquer frequentador de estádio de futebol.

Mesmo com o Estatuto em vigor, alguns acidentes ainda ocorrem em estádios brasileiros, como a morte de 8 torcedores vítimas de desmoronamento de arquibancada no estádio Fonte Nova, em Salvador, no ano de 2007 (REIS, 2010).

Diante destes fatos, a CBF então solicitou ao sistema CONFEA/CREA (Conselho Federal de Engenharia, Arquitetura e Agronomia e Conselho Regional de Engenharia, Arquitetura e Agronomia) que construísse diretrizes básicas para a inspeção dos estádios de futebol (PUJADAS; GATTO, 2010). Apenas no ano de 2009 foram estabelecidos estes requisitos mínimos para as inspeções através do Decreto $n^{0}$ 6.795/2009 (BRASIL, 2009a), no qual foi designada uma Portaria contendo todos os laudos com exigências a serem contempladas pelos estádios brasileiros (BRASIL, 2009b).

A partir do panorama da evolução das regulamentações europeias e brasileira podemos apontar um atraso muito grande no que diz respeito à implementação do EDT e a promulgação dos critérios e laudos para que os locais de prática possam ser fiscalizados de forma satisfatória.

Até hoje se verifica que várias das determinações do EDT não são cumpridas. Em pesquisa realizada por Reis (2010), a autora constata que cerca de metade das previsões que constam na lei não são cumpridas, como higiene em banheiros, forma de venda de ingressos, segurança dos torcedores dentro e fora dos estádios, número suficiente de locais para alimentação, dentre outros.

Segundo Curi et. al. (2008) o EDT não tem sido cumprido integralmente em parte porque seu público-alvo, os torcedores, desconhece seus direitos como consumidores do espetáculo esportivo. Em entrevista realizada pelos autores com os torcedores, apenas $1,5 \%$ afirmaram conhecer o EDT integralmente enquanto que 39,3\% não chegam nem a conhecê-lo, o que dificulta sua fiscalização e denúncia de descumprimento da Lei por parte dos organizadores.

É interessante observar que há quinze anos, mais precisamente em maio de 1995, o município de São Paulo promulgava uma lei que obrigava os estádios de futebol, dentre outros estabelecimentos, a comercialização de ingressos e a manutenção de toda a lotação do espaço destinado aos espectadores com numeração fixa (SÃO PAULO, 
1995). Segundo esta Lei, a $n^{\circ} 11.786$, ficou estabelecido o prazo de 120 dias para que os administradores dos estádios pudessem se adequar às novas exigências, ou seja, desde 1995 já se exigia este tipo de organização para os estádios de futebol na cidade de São Paulo.

No entanto, o que se observa é que ações como a numeração de todos os assentos nos estádios paulistas deu-se em parte apenas após a promulgação do EDT e posteriormente do Decreto $n^{0} 6.795$, já citado anteriormente, e da Portaria $\mathrm{n}^{\mathrm{o}} 124$ de 2009, que estabelece os requisitos mínimos a serem contemplados nos laudos de segurança, vistoria de engenharia, prevenção e combate de incêndio e condições sanitárias.

Em estudo realizado pelo Sindicato Nacional das Empresas de Arquitetura e Engenharia (SINAENCO), o estado de abandono em que se encontram os estádios brasileiros se confirma:

- 90\% dos estádios não oferecem acesso aos portadores de necessidades especiais;

- 85 \% não possuem vestiários adequados;

- 95\% possuem sanitários em condições ruins ou péssimas;

- 82\% não possuem assentos conforme o estabelecido pelo Caderno de Encargos da FIFA.

A própria percepção dos frequentadores dos estádios reafirma o não cumprimento dos artigos previstos no EDT. Em pesquisa realizada por Silva et. al. (2007), na qual foram entrevistados 120 torcedores frequentadores do estádio Governador Magalhães Pinto (Mineirão), em Belo Horizonte, 44,2\% afirmaram não se sentirem seguros em algum momento (antes, durante ou após o termino da partida) quando vão ao estádio. Isto reflete o que o torcedor encontra quando se desloca até as instalações para assistir a uma partida de futebol.

Interessante lembrar que, em detrimento das alterações ocorridas em 2010 no EDT, através da Lei no 12.299 de 27 de julho, a prevenção da violência passa a ser responsabilidade tanto do poder público como das federações e confederações, dos próprios clubes organizadores dos eventos, bem como daqueles que promovam, coordenem e participem dos eventos esportivos (BRASIL, 2010). Observa-se que apesar da Lei delegar a responsabilidade de garantia de segurança, ela apresenta uma lista de responsáveis, o que dificulta apontar, em caso de qualquer ocorrência, qual o responsável real pela garantia da segurança do torcedor.

Quanto a qualidade dos serviços prestados, estudo de Trein (2004), 
relativo à qualidade dos serviços prestados aos frequentadores do estádio do Beira-Rio em Porto Alegre, aponta deficiências nos serviços de limpeza e manutenção dos sanitários, nos preços praticados nos estacionamentos e bares, no conforto e limpeza dos assentos, no retorno de reclamações feitas a ouvidoria, nas opções e tempo de atendimento nos locais de alimentação, dentre outras.

Em suma, o que existe no Brasil em termos de instrumento de gestão para os estádios e os espetáculos esportivos realizados nesse tipo de instalação restringe-se a uma portaria que apresenta os laudos com os requisitos mínimos a serem contemplados nos estádios brasileiros. São previstas apenas questões que abordam segurança do público contra a violência (câmeras de segurança, policiamento, sistemas contra invasão), falha nas estruturas (condições das instalações no que diz respeito ao estado de conservação, perigos de desabamento, infiltrações, dentre outros), incêndios, higiene e condições sanitárias (condições dos banheiros, se estes são suficientes, se há lanchonetes e se estas possuem condições sanitárias satisfatórias para o armazenamento e preparo de alimentos).

Outro aspecto que pode ser destacado é que não há nenhuma menção às instalações destinadas à imprensa (apenas uma preocupação sob a ótica da segurança a respeito do portão de acesso destinado à mídia). Quanto ao conforto aos torcedores, só há alusão aos assentos, mas ainda assim são considerados os torcedores que permanecem em pé, o que já é proibido pela FIFA. Nesta portaria também não há preocupação com o atendimento ao público no que diz respeito ao oferecimento de locais para alimentação, compras ou entretenimento dentro ou próximo aos estádios.

Caracteriza-se, assim, este documento como um regulador técnico, o que hoje não satisfaz às necessidades impostas tanto pelas entidades organizadoras de eventos internacionais, quanto pela imprensa, que necessita cada vez mais de uma infraestrutura de ultima geração para realizar a transmissão e cobertura durante os megaeventos esportivos e o próprio público frequentador dos estádios, que está cada vez mais exigente e pede por estruturas que lhe ofereçam o máximo de conforto, segurança e entretenimento.

Este quadro reflete o que é encontrado nos diversos estádios do Brasil e demonstra o quanto que se tem que mudar no país que sediará a Copa de Mundo de 2014. 


\section{Considerações Finais}

A análise das regulamentações brasileiras e a comparação com as regulamentações européias e da FIFA, retratadas em avaliações e pesquisas, apontam deficiências tanto em termos de estrutura quanto de serviços nos estádios de futebol em todo o Brasil.

Mesmo com o EDT e a discriminação dos requisitos mínimos a serem contemplados nos estádios brasileiros, pelo Decreto $n^{0} 6.795$ e pela Portaria $\mathrm{n}^{\circ} 124$ de 2009, o que podemos constatar é que a situação dessas estruturas no Brasil beira ao abandono por parte de seus gestores.

Estas leis, ao contrário do que aconteceu no continente Europeu, demoraram muito a serem promulgadas e o mais grave, implementadas. A demora em se definir quais seriam os critérios para as inspeções nos estádios e os órgãos competentes para tal só fez com que a implementação do EDT demorasse ainda mais tempo para se concretizar. Da mesma forma, a própria lei sofreu desmoralização e dá a impressão de falta de impunidade aos gestores dos estádios e dos espetáculos esportivos, fazendo com que, apesar da lei já estar em vigor, não sejam respeitadas as normas que ela estabelece.

$\mathrm{Na}$ Europa, o cumprimento das orientações contidas nos cadernos de encargos da UEFA faz prevalecer a boa estrutura e os bons serviços prestados nos estádios. No Brasil o que se vê é uma preocupação às vésperas de um grande evento esportivo, a Copa de Mundo de 2014.

Hoje, os cadernos de encargos e requisitos exigidos tanto pela FIFA como pela UEFA para comportar os jogos destas entidades já se preocupam com questões além da segurança e higiene no recinto do jogo.

Podemos concluir que, dentre outros motivos, a ineficiência das leis para regulamentar os estádios de futebol no Brasil é um dos fatores que contribuem para a deficiência encontrada atualmente nestes locais. As diversas modificações ocorridas nas leis e determinações europeias decorreram da transformação pela qual o esporte, em especial o futebol, passou ao longo dos anos. O que vimos acontecer no Brasil são instalações paradas no tempo em que foram construídas.

Faz-se necessário agora a reforma e renovação das instalações existentes no país para que estas possam receber jogos da Copa das Confederações e da Copa do Mundo em 2014, mas também se faz necessária uma revisão das leis que regulamentam estes espaços a fim de garantir a segurança e boa estrutura nos mesmos e contribuir para que haja uma 
renovação e evolução efetiva e sustentável no que tange a gestão das instalações esportivas no Brasil.

\title{
Regulation and Management of Football Stadiums in Brazil
}

\begin{abstract}
Brazilian laws that deal with standards of protection and defense of sport supporters predict the right to security in the stadium, accessibility, cleanliness and quality of the stadium facilities, among other factors (BRAZIL, 2003, 2010), but the reality is far from it. This study aimed to examine the regulations for Brazilian football stadiums and compare them to European and FIFA. Through documentary and bibliographic analysis it was noted that Brazilian regulations, compared with UEFA and FIFA, show delay and inefficiency, both in terms of structure and adequacy of services in a football stadium. We conclude that this inefficiency is one of the factors contributing to the poor conditions in which Brazilian football stadiums are found, resulting in limitations in terms of its management.
\end{abstract}

Keywords: Sport Facilities - Football Stadium - Regulation

\section{La Regulación y Gestión de los Estadios de Fútbol en Brasil}

\section{Resumen}

Las leyes brasileñas que tienen que ver con las normas de protección y defensa de los aficionados predecir el derecho a la seguridad del estadio, la accesibilidad, la limpieza y la calidad de las instalaciones físicas de la cancha, entre otros factores (Brasil, 2003, 2010), pero la realidad es mucho menos . Este estudio tuvo como objetivo examinar el reglamento de los estadios de fútbol de Brasil y compararlos con los europeos y la FIFA. A través del análisis documental y la literatura encontró que las regulaciones de Brasil en comparación con un retraso enlace la UEFA y la FIFA y la ineficiencia, tanto en términos de estructura y adecuación de los servicios en un estadio de fútbol. Se concluye que esta ineficiencia es uno de los factores que contribuyen al mal estado que se encuentran en estadios de fútbol, dando lugar a limitaciones en términos de su gestión.

Palabras clave: Instalaciones Deportivas - Estadios de Fútbol - Regulación

\section{Referências}

BRASIL. Lei no 10.671, de 15 de maio de 2003. Dispõe sobre o estatuto dos direitos do Torcedor. Diário Oficial da República Federativa do Brasil. Poder Executivo, Brasília, DF, 15 de maio de 2003.

. Decreto $\mathrm{n}^{0} 6.795$ de 16 de março de 2009. Regulamenta o art. 23 da Lei $\mathrm{n}^{\circ} 10.671$, de 15 de maio de 2003, que dispõe sobre o controle das condições de segurança dos estádios desportivos. Diário 
Oficial da República Federativa do Brasil. Poder Executivo, Brasília, DF, 16 de março de 2009a.

. Portaria $\mathrm{n}^{0}$ 124, de 17 de julho de 2009. Estabelece requisitos a serem contemplados nos laudos técnicos previstos no Decreto $\mathrm{n}^{\mathrm{o}}$ 6.795/2009. Diário Oficial da República Federativa do Brasil. Ministério do Esporte, Brasília, DF, 17 de julho de 2009b.

. Lei $\mathbf{n}^{\circ}$ 12.299, de 27 de julho de 2010. Dispõe sobre medidas de prevenção e repressão aos fenômenos de violência por ocasião de competições esportivas. Altera a Lei $\mathrm{n}^{\mathrm{o}} 10.671$, de 15 de maio de 2003, e dá outras providências. Diário Oficial da República Federativa do Brasil. Poder Executivo, Brasília, DF, 27 de julho de 2010.

CONFEDERAÇÃO BRASILEIRA DE FUTEBOL (CBF). Cadastro Nacional de Estádios de Futebol. Rio de Janeiro, 15 de setembro de 2009.

CURI, M. et. al. Observatório do Torcedor: o Estatuto. Revista Brasileira de Ciência do Esporte. Campinas, v. 30, n. 1, p. 25-40, setembro de 2008.

FÉDÉRATION INTERNATIONALE DE FOOTBALL ASSOCIATION, Football Stadiums: Technical recommendations and requirements. Zurich, 2007, 4ed.

HOLZMEISTER, A. A nova economia do futebol: uma análise do processo de modernização de alguns estádios brasileiros. 2005. Rio de Janeiro, 2005, 114f. Dissertação (Mestrado em Antropologia Social). Universidade Federal do Rio de Janeiro, UFRJ, Rio de Janeiro, 2005.

LA CORTE, C. Estádios brasileiros de futebol: uma análise de desempenho técnico, funcional e de gestão. 2007. Tese (Doutorado em Arquitetura). Faculdade de Arquitetura e Urbanismo, USP, São Paulo, 2007.

MULlin, B. J.; HARDY, S.; SUTTON, W. A. Sports Marketing. Champaign: Human Kinetics, 2000.

O ESTADO DE SÃO PAULO. Outras Tragédias em Estádios Marcaram o Futebol Brasileiro, 26 de novembro de 2007. Disponível em: $\quad<$ http://www.estadao.com.br/noticias/esportes,outras-tragedias- 
em-estadios-marcaram-o-futebol-brasileiro,85783,0.htm>. Acesso em: 27 agosto 2010 .

PUJADAS, F. Z. A.; GATTO, O. A. Inspeção predial em estádios de futebol: Uma visão sistêmica da segurança. Revista Construção. Disponível em: $<$ http://revista.construcaomercado.com.br/negocios-incorporacao-contrucao/93/artigo130228-1.asp >. Acesso em: 10 junho 2010 .

REIS, H. H. B. Os espectadores de futebol e a problemática da violência relacionada à organização do espetáculo futebolístico. Revista Paulista de Educação Física. São Paulo, v.17, n. 2, p. 85-92, jul./dez. 2003.

. O espetáculo futebolístico e o estatuto de defesa do torcedor. Revista Brasileira de Ciências do Esporte. Campinas, v. 31, n. 3, p. 111-130, 2010.

RIBEIRO, F. T., Instalações Esportivas - Planejamento e Desenvolvimento In: DACOSTA, L.(org.), Atlas do Esporte no Brasil. Rio de Janeiro: CONFEF, 2006.

SÃO PAULO. Lei $\mathbf{n}^{\mathbf{0}} \mathbf{1 1 . 7 8 6}$, de 26 de maio de 2006. Torna obrigatória em todos os cinemas, cineclubes, cinematecas, teatros, casas de espetáculo, estádios de futebol, ginásios de esportes e demais estabelecimentos congêneres a manutenção de toda a lotação com lugares numerados. Câmara Municipal. São Paulo, SP, 1995.

SILVA, S. R.; NICÁCIO, L. G.; SILVA JUNIOR, M. S. L.; VIEIRA, Y. V. G. Futebol e Torcida: um estudo sobre o Estatuto de Defesa do Torcedor no Campeonato Brasileiro de 2006 na cidade de Belo Horizonte. EF Deportes Revista Digital, www.efdeportes.com/Buenos Aires, ano 12, $\mathrm{n}^{\mathrm{o}} 107,2007$.

SIR NORMAN CHESTER CENTRE FOR FOOTBALL RESEAR$\mathrm{CH}$. Football stadia after Taylor. Leicester: University of Leicester, 2002.

SPAMPINATO, A., Stadium History. Disponível em: $<$ http://www.worldstadiums.com/stadium_menu/architecture/historic_stadiums.shtml>. Acesso em: 14 abril 2010. 
TREIN, F. L. Qualidade dos serviços oferecidos e prestados em um estádio de futebol em dias de jogos: um estudo de caso. Porto Alegre, RS, 2004. Dissertação (Mestrado Profissionalizante em Engenharia) Escola de Engenharia, UFRGS, Porto Alegre, 2004.

Union of European Football Associations. Binding Safety and Security Instructions. Nyon, Edition 2004, dezembro de 2003.

. UEFA Safety and Security Regulations. Nyon, Edition 2006, Outubro de 2006a.

. UEFA Stadium Infrastructure Regulations. Nyon, Edition 2006, Outubro de 2006b.

. UEFA Stadium Infrastructure Regulations. Nyon, Edition $\overline{2010,} 24$ de março de 2010a.

. UEFA Club Licensing and Financial Fair Play Regulations. Nyon, Edition 2010, 27 de maio de 2010b.

UNIÃO EUROPÉIA. European Convention on Spectator Violence and Misbehaviour at Sports Events and Particular at Football Matches. Strasbourg, European Treaty Series - No. 120, 19.VIII.1985

VERGARA, S.C. Projetos e Relatórios de Pesquisa em Administração. São Paulo: Atlas, 2006.

Recebido em: 08/06/2011

Revisado em: 09/06/2011

Aprovado em: 01/08/2011

Endereço para correspondência

flaviacb@usp.br

Flávia da Cunha Bastos

Universidade de São Paulo

Escola de Educação Física e Esporte, Departamento de Esporte.

Av. Prof. Mello Moraes, 65

Butantã

05508-900 - Sao Paulo, SP - Brasil 